\title{
Application of Multivariate Analysis in the Evaluation of Metals Distribution in Soil from Awwal Mining Site Kebbi, Nigeria
}

\author{
${ }^{* 1}$ G. Shehu and 2I. B. Koki \\ 1Department of Physics, Federal College of Education (Technical) Gusau, Zamfara Nigeria, \\ 2Department of Chemistry, Yusuf Maitama Sule University, Kano PMB 3220 Kano, Nigeria \\ [Corresponding Author: E-mail: summiteducation2004@yahoo.com; $\mathbf{Z}:+2347038336717]$
}

\begin{abstract}
Multivariate statistical techniques such as principal component analysis (PCA), factor analysis (FA), and hierarchical cluster analysis (HCA) were utilized for the evaluation of metal distribution and variations in the soil at Awwal mining site. PCA was used to determine a reduced number of three principal components (PC) indicating about $82 \%$ of the total variation in the soil samples. The result of FA justifies the results of the PCA obtained. HCA classified the soil samples at the sites into two clusters, with cluster one having the higher metal levels, while cluster two had low metal levels but characterized with dominant toxic heavy metals (As and $\mathrm{Pb}$ ). The results of the multivariate analysis showed that natural percentage abundance in soil and mineral composition of the mining ores were the main sources of the metals under study. Due to high metal levels in the soils, disposal and management of the mining waste/tailings and rehabilitation of the mining site after closure of mining should be done with care and caution to avoid leaching of the toxic metals to surface and underground water for the protection of health and safety of the neighboring community.
\end{abstract}

Keywords: Soil, Metals, Mining, Multivariate analysis, Awwal.

\section{INTRODUCTION}

Mineral exploration is one of the main sources of income to government and local inhabitants. However, it poses challenges in Northwestern part of Nigeria due to the methods of mining employed, which involves the use of crude implements, as well as ignorance or lack of proper understanding of metal levels and distributions in soils of the mining districts. This results in poor safety and improper disposal of the mining wastes without considering the environmental and human health consequences. Mining activities in recent time have been of concern to scientists in developed and developing countries around the world due to the associated environmental pollution (Dong et al., 2001). Mineral extraction has caused serious environmental pollution, especially contamination due to metalloids and heavy metals (Acosta et al., 2011). Therefore, evaluation of spatial variability of the metals in soil of the mining area is essential for better understanding of the relationship between the variables, and for successful land management after closure of the mining operation (Burgos et al., 2008).
One of the consequences of soil pollution due to mining is health complications such as poisoning and subsequent death. These cases were reported in some mining districts in Zamfara State where hundreds of children died as a result of high blood lead level (Dooyema et al., 2012). This sad incidence could have been averted by proper understanding of levels and metal distributions in soil of the mining zones. The local miners had no idea on the metal levels in waste/tailings and its distribution at different stages of mining, thereby indiscriminately discarding the waste posing health complications to the nearby communities, and abandoning the excavated sites without future plans for rehabilitation. Leaching of toxic metals associated with mining was reported in surface and underground water of neighboring settlements, thereby elevating the metal levels far beyond recommended permissible limits in drinking water (Bhuiyan et al., 2010; Malm et al., 1990; Razo et al., 2004; Tiwary and Dhar, 1994). Contamination of agricultural soils due to mining raises the metal concentrations to significant levels, which could also be a threat to humans through food chain (Garcia-Sanchez and Alvarez-Ayuso, 2003; Sultana et al., 2016; Tembo et al., 2006). Poor 
or lack of rehabilitation policies at mining sites to conserve the environment has been described as a challenge to developing countries in a recent time (Hancock, 2004; Lubke and Avis, 1999).

The application of multivariate statistical analysis offers a better understanding of the distribution of metals, and classification of soil based on the metal levels (Acosta et al., 2011). Multivariate statistical analysis extracts important information from large data with variations, without missing useful information by recognizing representative parameters and identifying the most significant parameter responsible for the variation (Juahir et al., 2010; Juahir et al., 2011; Koki et al., 2017; Low et al., 2016). The most commonly used multivariate statistical techniques in environmental studies are; PCA, FA, and HCA. PCA is a pattern recognition technique that interprets the variance within a large set of intercorrelated variables by converting them into a smaller set of independent variables. It provide information on the most significant parameters used to describe the entire data set (Simeonova et al., 2003). This technique has been used to evaluate the relationship between metal pollutants and soil properties (Borůvka et al., 2005; Peris et al., 2008). FA is a data reduction technique which suggests how many variables are important to explain the variance in the data (Alkarkhi et al., 2009). The PCs generated by PCA are sometimes not easily interpreted, it is therefore advisable to rotate the PCs (eigen value $>1$ ) by varimax rotation so as to reveal any hidden latent variable using FA (Juahir et al., 2011). HCA is a multivariate technique applied on the data set to classify objects (sampling sites) based on their similarities. The aim is to group similar objects within each cluster, however, the clusters are dissimilar to each other (Zhao et al., 2012).

The objectives of this research were to determine the levels and metal variations in the soil of the mining zones, and to examine the distribution of the metals across the mining sites so as to give an idea on the safety of the mining waste, and rehabilitation of the mining zone.

\section{MATERIAL AND METHODS \\ Study Area}

Preliminary surveys were conducted to give direction to areas at which soil/tailing samples were collected. Awwal is located in Fakai local government (Figure 1) on the southern part of Kebbi state between longitudes $4^{\circ} 45^{\prime}$ and $4^{\circ} 50^{\prime}$ $E$ of the prime meridian and latitudes $11^{\circ} 35^{\prime}$ and $11^{\circ} 40^{\prime} \mathrm{N}$ of the equator. The geology of the study area revealed that main ore minerals are gold, galena, arsenopyrite, pyrite, chalcopyrite and iron oxides deposits (Ramadan and Abdel Fattah, 2010).

\section{Sampling and Sample Pretreatment}

Soil sampling procedure involves the use of an auger. The instrument was used in each of the cases to burrow to a depth of about $20-30 \mathrm{~cm}$ of chiseled rock materials. At each sampling location, three sub-samples were collected, mixed together to form a composite sample. Each soil composite sample made was emptied into a black polyethylene-sampling bag, tied and labeled. The bags were double-bagged to reduce chances of cross-contamination of samples. The consciousness of knowledge of leaching effect was the guiding factor in the sampling procedure. A total of 57 samples were collected for analysis, weighed and grounded in an agate mortar. Binder (Poly Vinyl Chloride dissolved in Toluene) was added to the sample, carefully mixed and pressed in a hydraulic press into a pellet.

\section{Procedure for Analysis of Samples}

Mini $\mathrm{Pal}$ is a compact energy dispersive $\mathrm{x}$-ray spectrometer designed for the elemental analysis of a wide range of samples. The system is controlled by a computer running the dedicated Mini pal analytical software. The Mini pal 4 version used in this study is PW4030 xray spectrometer, which is energy dispersive microprocessor controlled analytical instrument designed for the detection and measurement of elements in a sample (solids, powders and liquids). The prepared pellet was loaded in the sample chamber of the spectrometer and 
voltage (30kv max.) and a current (1mA max.) is applied to produce the $x$-rays to excite the sample for a preset time $30 \mathrm{~min}$. The spectrum from the sample was analyzed to determine the concentration of the elements in the sample (Tursunov et al., 2015; Isah et al., 2017).

\section{Statistical Analysis}

Descriptive statistics and analysis of variance (ANOVA) was carried out using MS Excel 2010, while JMP Pro 12 was used for the multivariate statistical analysis.



Figure 1. Map of the study area showing sampling location

\section{RESULTS AND DISCUSSION}

The statistical summary of studied metals in soil samples is presented in Table 1. The mean and standard deviation is displayed for the three sample locations. The results of ANOVA showed a significant difference $(P<0.05)$ indicating notable differences in mean metal concentration of the soils. The concentration of Si was significantly the most dominant, while $\mathrm{Cu}$ concentration was the least. High $\mathrm{Si}$ concentration could be attributed to high percentage natural abundance, which accounted for about $28 \%$ of the earth crust ( $\mathrm{Ma}$, 2005; Martin, 2013), it is considered inert and essentially non-toxic (Nielsen, 2009). Rb was also very high in the soils under study, and considered non-essential for any living organism. Other metals of much concern are $\mathrm{As}$ and $\mathrm{Pb}$ which are very toxic to humans and potential carcinogen (Kalia and Flora, 2005). Soil samples at the milling shed contains higher concentration of $\mathrm{As}$, while $\mathrm{Pb}$ was higher at the sedimentation zone. The values of these metals reported in this study were alarming, and are significantly higher than permissible concentrations in soil based on risk of exposure (Dudka and Miller, 1999).

A clear metal distribution at the sites is clearly shown in Figure 2 using PCA biplot indicating that mining cafe has the highest variation of most metals studied. Three significant PCs with eigen value $>1$ were extracted with a total of $81.69 \%$ of the total variance in the soil data set (Table 2). The first principal component (PC1) accounting for $49.20 \%$ of the total variation in the entire data set and is strongly loaded with $\mathrm{Fe}, \mathrm{K}, \mathrm{Al}$, and $\mathrm{Ti}$. These are metals representing high percentage abundance in the mining area with respect to natural geological distribution. The second PC accounting for $22.40 \%$ of the total variance was dominated with toxic metals $\mathrm{As}$ and $\mathrm{Pb}$ from the mineral ore under exploration (Da Silva et al., 2004). 
Shehu and Koki: Application of Multivariate Analysis in the Evaluation of Metals...

These metals are not required by organisms and obvious source of contamination to the environment, hence the need to properly discard the mining waste. The third PC was much correlated to As and Al which represent metals associated with ore variability.

Table 1. Mean metal concentration in soil samples at Awwal mining site $\left(\times 10^{4} \mathrm{ppm}\right)$

\begin{tabular}{cccc}
\hline Element & $\begin{array}{c}\text { Milling Shed } \\
\text { (MS) }\end{array}$ & $\begin{array}{c}\text { Mining Cafe } \\
\text { (CS) }\end{array}$ & $\begin{array}{c}\text { Sedimentation } \\
\text { Zone (TS) }\end{array}$ \\
\hline $\mathrm{Al}$ & $2.40 \pm 0.50$ & $6.02 \pm 0.86$ & $1.88 \pm 0.86$ \\
$\mathrm{Si}$ & $37.58 \pm 1.92$ & $26.32 \pm 5.49$ & $38.40 \pm 5.15$ \\
$\mathrm{~K}$ & $1.49 \pm 0.26$ & $5.46 \pm 1.93$ & $2.04 \pm 0.78$ \\
$\mathrm{Ti}$ & $0.17 \pm 0.02$ & $0.97 \pm 0.57$ & $0.66 \pm 0.15$ \\
$\mathrm{Fe}$ & $4.57 \pm 1.88$ & $7.80 \pm 4.76$ & $2.11 \pm 0.51$ \\
$\mathrm{Cu}$ & $0.09 \pm 0.02$ & $0.06 \pm 0.02$ & $0.05 \pm 0.02$ \\
$\mathrm{Rb}$ & $8.59 \pm 3.20$ & $6.27 \pm 5.49$ & $20.11 \pm 7.49$ \\
$\mathrm{Rh}$ & $0.45 \pm 0.17$ & $0.73 \pm 0.27$ & $0.67 \pm 0.35$ \\
$\mathrm{~Pb}$ & $1.70 \pm 1.12$ & $1.75 \pm 0.35$ & $2.86 \pm 0.91$ \\
$\mathrm{As}$ & $0.31 \pm 0.15$ & $0.19 \pm 0.09$ & $0.09 \pm 0.06$ \\
\hline
\end{tabular}

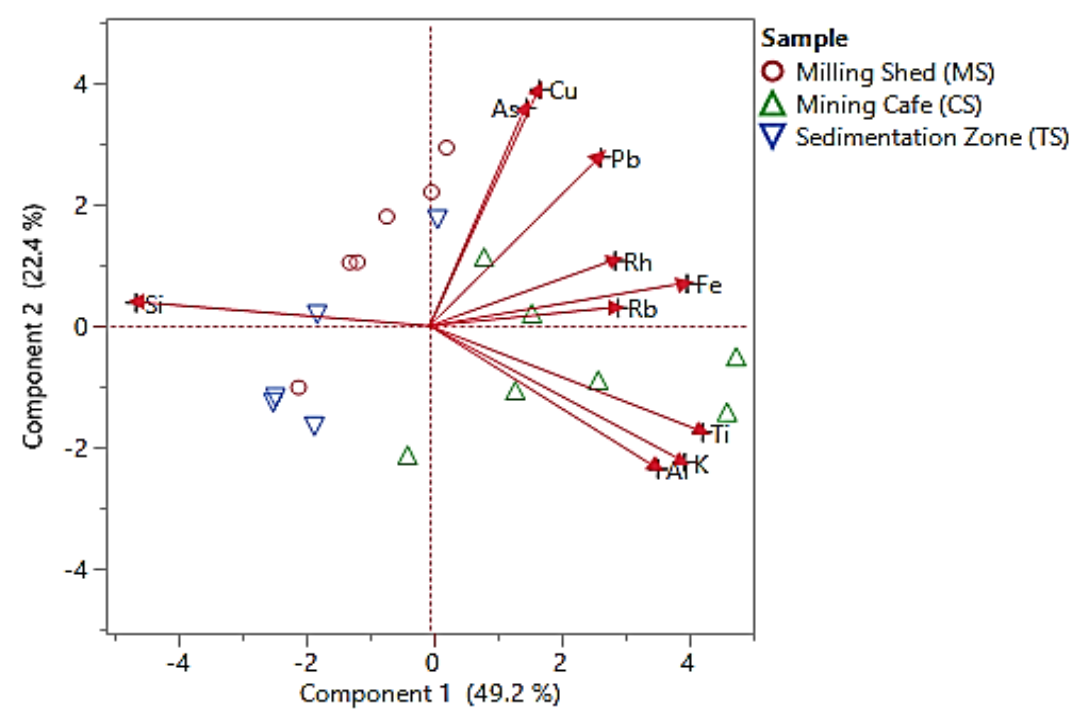

$\square$ Label variables

Figure 2. Bi plot of elemental distribution at the Awwal mining site

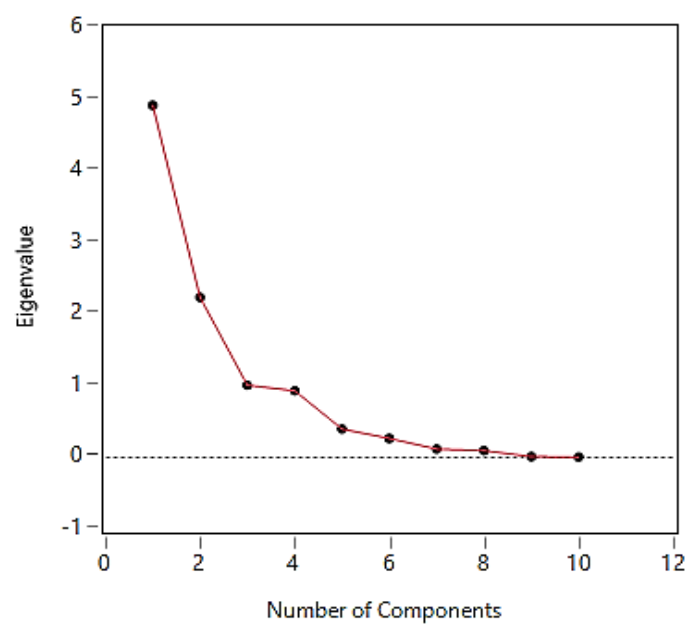

A scree plot was used to give visual support in selection of the appropriate number of PCs to be retained. The sharp elbow bent determine the number of significant PCs, other subsequent PCs are not considered (Shiker, 2012). The elbow point was noted at the third component as shown in Figure 3.

Figure 3. Scree plot 
Table 2: Principal component loadings of 10 variables on the significant PCs in Awwal mining site

\begin{tabular}{llll}
\hline Variables & PC1 & PC2 & PC3 \\
\hline $\mathrm{As}$ & 0.14 & 0.50 & 0.39 \\
$\mathrm{Cu}$ & 0.16 & 0.55 & 0.13 \\
$\mathrm{Fe}$ & 0.38 & 0.10 & 0.23 \\
$\mathrm{~K}$ & 0.37 & -0.31 & 0.19 \\
$\mathrm{~Pb}$ & 0.25 & 0.39 & -0.19 \\
$\mathrm{Rb}$ & 0.28 & 0.04 & -0.75 \\
$\mathrm{Rh}$ & 0.27 & 0.15 & -0.09 \\
$\mathrm{Si}$ & -0.43 & 0.06 & 0.20 \\
$\mathrm{Al}$ & 0.33 & -0.33 & 0.31 \\
$\mathrm{Ti}$ & 0.39 & -0.24 & 0.08 \\
Eigen Value & 4.92 & 2.24 & 1.00
\end{tabular}

\begin{tabular}{lrrr} 
Variability (\%) & 49.20 & 22.40 & 10.09 \\
Cumulative (\%) & 49.20 & 71.60 & 81.69 \\
\hline Bold PC loading are significant $(>0.30)$
\end{tabular}

The results of the rotated factor loading (Table 3) revealed that first VF explained $55.26 \%$ of the total variance and was best represented by $\mathrm{Fe}, \mathrm{K}, \mathrm{Al}$, Ti. This factor represents metals high percentage abundance in the earth crust. VF2 had a strong loading on $\mathrm{As}, \mathrm{Cu}, \mathrm{Fe}$, and $\mathrm{Pb}$ and explained $23.59 \%$ of the total variance. As and $\mathrm{Pb}$ are of much environmental concern, and are usually associated with the local gold mining in the area (Koki et al., 2017). This implies that soil and tailings in the zones under study should be properly discarded and the excavated sites rehabilitated to avoid metal leaching to underground water. $\mathrm{Cu}$ and $\mathrm{Fe}$ could possibly be influenced by weathering and leaching of rocks. VF3 explained $10.42 \%$ of the total variation with a strong positive loading on $\mathrm{Rb}$ and negative loading on Si which could be due to differences in the geogenic distributions of the metals in the soils.

Table 3:. Factor loadings of 10 variables on the significant varimax-rotated PCs in Awwal mining site

\begin{tabular}{|c|c|c|c|}
\hline Variables & VF 1 & VF 2 & VF 3 \\
\hline As & 0.01 & 0.81 & -0.06 \\
\hline $\mathrm{Cu}$ & -0.05 & 0.87 & 0.10 \\
\hline $\mathrm{Fe}$ & 0.67 & 0.55 & 0.17 \\
\hline K & 0.96 & -0.02 & 0.16 \\
\hline $\mathrm{Pb}$ & 0.11 & 0.64 & 0.45 \\
\hline $\mathrm{Rb}$ & 0.20 & 0.08 & 0.94 \\
\hline $\mathrm{Rh}$ & 0.34 & 0.41 & 0.29 \\
\hline $\mathrm{Si}$ & -0.74 & -0.26 & -0.61 \\
\hline $\mathrm{Al}$ & 0.93 & -0.05 & 0.02 \\
\hline $\mathrm{Ti}$ & 0.91 & 0.07 & 0.29 \\
\hline Eigen Value & 4.84 & 2.07 & 1.01 \\
\hline Variability (\%) & 55.26 & 23.59 & 10.42 \\
\hline Cumulative (\%) & 55.26 & 78.85 & 89.27 \\
\hline
\end{tabular}

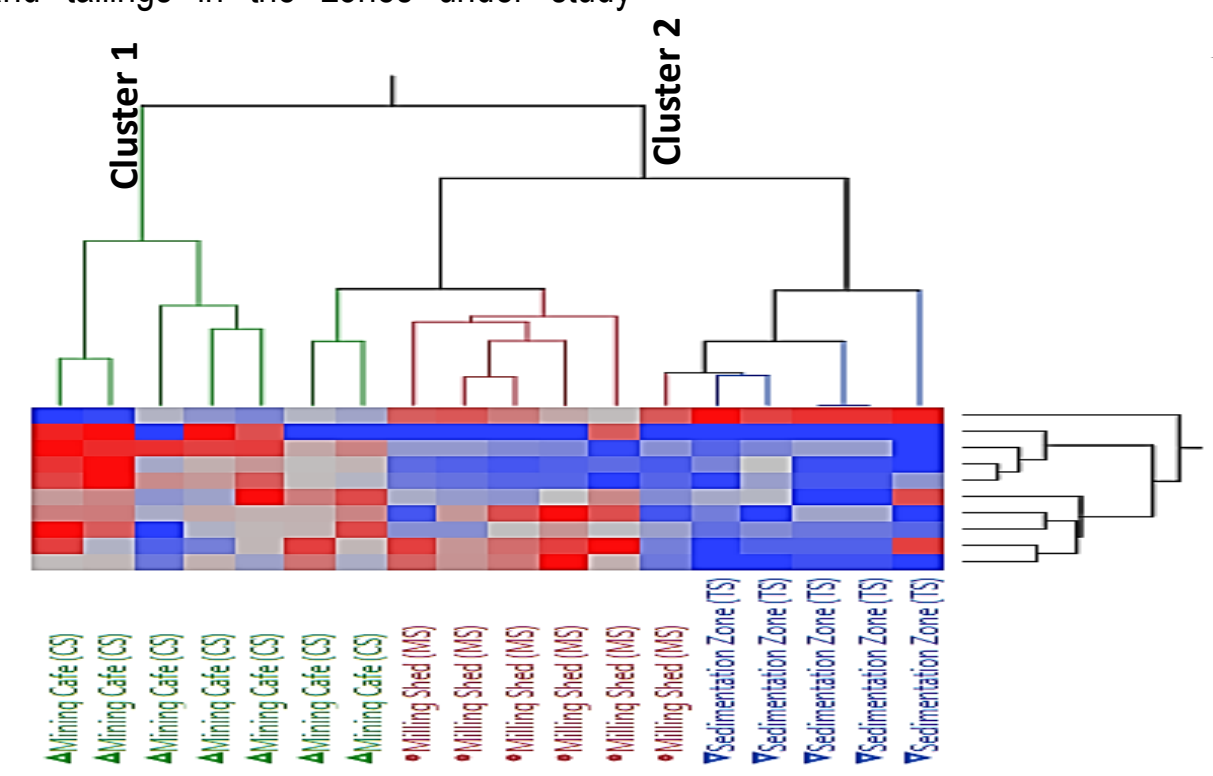

Figure 4: Two-way HCA of the metals in soil samples 
Application of two-way HCA using ward's method shows grouping among the sites with the corresponding metal concentrations in Figure 4. The samples were grouped into two major clusters 1 and 2; cluster 2 was further grouped into two sub clusters. Cluster overlap was observed in cluster 2 which could be attributed to unequal distribution of the metals at some locations in the mining sites. Many researchers reported differences in mineral compositions of soil and ores at various locations (Alloway, 2013; Naldrett et al., 1982; Paul, 2014). It can be inferred from Figure 4 that mining zone contains dominantly $\mathrm{K}, \mathrm{Ti}, \mathrm{Al}$, $\mathrm{Fe}$ and $\mathrm{Rb}$ which are metals with natural percentage abundance. Milling shed under cluster 2 contains $\mathrm{As}, \mathrm{Pb}$, and $\mathrm{Cu}$ associated with the mineral ores. Sedimentation zone contains the least metal loadings, but with strong $\mathrm{Si}$ concentrations attributed to the natural abundance in soils. The distribution of the metals under study reveals that soil samples in sedimentation zone though contain the highest $\mathrm{Pb}$ concentration is less polluted with other metals, followed by milling shed, and the most polluted is soil sample from mining café. HCA is therefore a good approach for the evaluation of pollution distribution among different groups (Koki et al., 2018).

The correlation matrix of metals obtained in soil from three zones in the mining site was examined. A strong positive correlation was observed between $\mathrm{As}, \mathrm{Cu}$, and $\mathrm{Pb}$, while $\mathrm{Si}$ has strong negative correlation with $\mathrm{Fe}, \mathrm{K}, \mathrm{Pb}, \mathrm{Rb}$, $\mathrm{Rh}, \mathrm{Al}$, and $\mathrm{Ti}$. This indicates that $\mathrm{Si}$ and toxic metals associated with mining share different origin sources. Metals such as $\mathrm{Pb}, \mathrm{Cu}$ and $\mathrm{As}$ occur in combination with other minerals in the ore (Acosta et al., 2011). Al and Ti have a strong positive correlation with $\mathrm{Fe}$ and $\mathrm{K}$. The correlation between the metals is further supported with the findings of PCA and FA (Table 2 and Table 3).

Table 4: Correlation matrix of selected elements in soil at Awwal mining site

\begin{tabular}{ccccccccccr}
\hline & As & Cu & Fe & K & Pb & Rb & Rh & Si & Al & Ti \\
\hline As & $\mathbf{1 . 0 0}$ & & & & & & & & & \\
$\mathrm{Cu}$ & $\mathbf{0 . 6 8}$ & $\mathbf{1 . 0 0}$ & & & & & & & & \\
$\mathrm{Fe}$ & 0.36 & 0.40 & $\mathbf{1 . 0 0}$ & & & & & & & \\
$\mathrm{K}$ & 0.01 & -0.01 & $\mathbf{0 . 5 7}$ & $\mathbf{1 . 0 0}$ & & & & & & \\
$\mathrm{Pb}$ & $\mathbf{0 . 5 9}$ & 0.46 & $\mathbf{0 . 5 4}$ & 0.12 & 1.00 & & & & & \\
$\mathrm{Rb}$ & 0.03 & 0.17 & 0.31 & 0.35 & 0.49 & 1.00 & & & & \\
$\mathrm{Rh}$ & 0.12 & $\mathbf{0 . 5 5}$ & 0.49 & 0.41 & 0.23 & 0.35 & 1.00 & & & \\
$\mathrm{Si}$ & -0.19 & -0.23 & $-\mathbf{0 . 7 3}$ & $-\mathbf{0 . 7 9}$ & $-\mathbf{0 . 5 5}$ & $-\mathbf{0 . 7 5}$ & $-\mathbf{0 . 5 2}$ & $\mathbf{1 . 0 0}$ & & \\
$\mathrm{Al}$ & 0.05 & -0.13 & $\mathbf{0 . 5 4}$ & $\mathbf{0 . 9 1}$ & 0.15 & 0.21 & 0.22 & -0.72 & $\mathbf{1 . 0 0}$ & \\
$\mathrm{Ti}$ & 0.03 & 0.05 & $\mathbf{0 . 7 5}$ & $\mathbf{0 . 9 2}$ & 0.23 & 0.47 & 0.42 & $-\mathbf{0 . 8 5}$ & $\mathbf{0 . 7 8}$ & $\mathbf{1 . 0 0}$ \\
\hline
\end{tabular}

\section{CONCLUSION}

The distribution of metals in Awwal mining site has been successfully analyzed using multivariate analysis. The results revealed variations in metal distribution among zones under study which is attributed to the differences in natural percentage abundance, and mineral composition of the targeted ore. PCA identified the variations and sources of the metals at the mining site, with dominance of $\mathrm{Al}$, $\mathrm{Fe}, \mathrm{K}$ and $\mathrm{Ti}$, and toxic metals As and $\mathrm{Pb}$. The result of factor analysis justifies the metal sources and variations. HCA categorizes the soil samples into two clusters with mining cafe in cluster 1, while milling shed and sedimentation zone formed separate group in cluster 2. Some metals show strong correlation with other metals signifying the same origin. Hence, the chemometric techniques applied in this study identified the possible source of the metals and there various distributions making the rehabilitation, remediation and management of the mining soil and wastes easier. These results serves as part of the preliminary data on the area upon which baseline data can be developed for the region under study, furthermore, it should be considered for future 
planning of the environmental monitoring by government and other enforcement agencies.

\section{REFERENCES}

Acosta, J., Faz, A., Martínez-Martínez, S., Zornoza, R., Carmona, D., and Kabas, S. (2011). Multivariate statistical and GISbased approach to evaluate heavy metals behavior in mine sites for future reclamation. Journal of Geochemical Exploration, 109(1): 8-17.

Alkarkhi, A. F., Ahmad, A., and Easa, A. M. (2009). Assessment of surface water quality of selected estuaries of Malaysia: multivariate statistical techniques. The Environmentalist, 29(3): 255-262.

Alloway, B. J. (2013). Sources of heavy metals and metalloids in soils Heavy metals in soils (pp. 11-50): Springer.

Bhuiyan, M. A., Islam, M., Dampare, S. B., Parvez, L., and Suzuki, S. (2010). Evaluation of hazardous metal pollution in irrigation and drinking water systems in the vicinity of a coal mine area of northwestern Bangladesh. Journal of Hazardous Materials, 179(1): 1065-1077.

Borůvka, L., Vacek, O., and Jehlička, J. (2005). Principal component analysis as a tool to indicate the origin of potentially toxic elements in soils. Geoderma, 128(3): 289-300.

Burgos, P., Madejón, E., Pérez-de-Mora, A., and Cabrera, F. (2008). Horizontal and vertical variability of soil properties in a trace element contaminated area. International Journal of Applied Earth Observation and Geoinformation, 10(1): 11-25.

Da Silva, E. F., Zhang, C., Pinto, L. S. S., Patinha, C., and Reis, P. (2004). Hazard assessment on arsenic and lead in soils of Castromil gold mining area, Portugal. Applied Geochemistry, 19(6): 887-898.

Dong, W. Q. Y., Cui, Y., and Liu, X. (2001). Instances of soil and crop heavy metal contamination in China. Soil and Sediment Contamination, 10(5): 497510.

Dooyema, C. A., Neri, A., Lo, Y.C., Durant, J., Dargan, P. I., Swarthout, T., Biya, O., Gidado, S.O., Haladu, S., Sani-Gwarzo, N., and Nguku, P.M. (2012). Outbreak of fatal childhood lead poisoning related to artisanal gold mining in northwestern Nigeria, 2010. Environmental Health Perspectives, 120(4): 601.

Dudka, S., and Miller, W. (1999). Permissible concentrations of arsenic and lead in soils based on risk assessment. Water, Air, and Soil Pollution, 113(1): 127-132.

Garcia-Sanchez, A., and Alvarez-Ayuso, E. (2003). Arsenic in soils and waters and its relation to geology and mining activities (Salamanca Province, Spain). Journal of Geochemical Exploration, 80(1): 69-79.

Hancock, G. (2004). The use of landscape evolution models in mining rehabilitation design. Environmental Geology, 46(5): 561-573.

Isah, H., Shehu, G., Sa'ad, L., and Galadima, A. (2017). Assessment of Heavy Metal Enrichment and Degree of Contamination in Play grounds and market of Duza Twin Village, Anka, Zamfara, Nigeria. SCIREA Journal of Energy, 2(2): 42-52.

Juahir, H., Zain, S. M., Aris, A. Z., Yusoff, M. K., and Mokhtar, M. B. (2010). Spatial assessment of Langat river water quality using chemometrics. Journal of Environmental Monitoring, 12(1): 287295.

Juahir, H., Zain, S. M., Yusoff, M. K., Hanidza, T. T., Armi, A. M., Toriman, M. E., and Mokhtar, M. (2011). Spatial water quality assessment of Langat River Basin (Malaysia) using environmetric techniques. Environmental Monitoring and Assessment, 173(1-4): 625-641.

Kalia, K., and Flora, S. J. (2005). Strategies for safe and effective therapeutic measures for chronic arsenic and lead poisoning. Journal of Occupational Health, 47(1): 121.

Koki, I. B., Low, K. H., Juahir, H., Azid, A., and Zain, S. M. (2017). Assessment of water quality of man-made lakes in Klang Valley (Malaysia) using chemometrics: the impact of mining. Desalination and Water Treatment, 74: 125-136.

Koki, I. B., Taqui, N. S., and Dhaif-Allah, M. A. H. (2018). A Chemometric Approach for the Distribution and Source Identification of 
Heavy Metals in Tannery Contaminated Soil. International Journal of Theoretical and Applied Sciences, 10(1): 01-08.

Low, K. H., Koki, I. B., Juahir, H., Azid, A., Behkami, S., Ikram, R., Mohammed, H.A., and Zain, S. M. (2016). Evaluation of water quality variation in lakes, rivers, and ex-mining ponds in Malaysia. Desalination and Water Treatment, 57(58): 28215-28239.

Lubke, R., and Avis, A. (1999). A review of the concepts and application of rehabilitation following heavy mineral dune mining. Marine Pollution Bulletin, 37(8): 546-557.

Ma, J. F. (2005). Plant root responses to three abundant soil minerals: silicon, aluminum and iron. Critical Reviews in Plant Sciences, 24(4): 267-281.

Malm, O., Pfeiffer, W. C., Souza, C. M., and Reuther, R. (1990). Mercury pollution due to gold mining in the Madeira River basin, Brazil. Ambio, 19(1): 11-15.

Martin, K. R. (2013). Silicon: the health benefits of a metalloid Interrelations between Essential Metal lons and Human Diseases (pp. 451-473): Springer.

Naldrett, A. J., Innes, D., Sowa, J., and Gorton, M. (1982). Compositional variations within and between five Sudbury ore deposits. Economic Geology, 77(6): 1519-1534.

Nielsen, F. H. (2009). Micronutrients in parenteral nutrition: boron, silicon, and fluoride. Gastroenterology, 137(5): S55-S60.

Paul, E. A. (2014). Soil microbiology, ecology and biochemistry: Academic press.

Peris, M., Recatalá, L., Micó, C., Sánchez, R., and Sánchez, J. (2008). Increasing the knowledge of heavy metal contents and sources in agricultural soils of the European Mediterranean region. Water, Air, and Soil Pollution, 192(1-4): 25-37.

Ramadan, T. M. and Abdel Fattah M. F. (2010). Characterization of gold mineralization in
Garin Hawal area, Kebbi State, NW Nigeria, using remote sensing. The Egyptian Journal of Remote Sensing and Space Sciences, 13: 153-163.

Razo, I., Carrizales, L., Castro, J., Díaz-Barriga, F., and Monroy, M. (2004). Arsenic and heavy metal pollution of soil, water and sediments in a semi-arid climate mining area in Mexico. Water, Air, and Soil Pollution, 152(1): 129-152.

Shiker, M. A. K. (2012). Multivariate Statistical Analysis. British Journal of Science, 6(1): 55-66.

Simeonova, P., Simeonov, V., and Andreev, G. (2003). Water quality study of the Struma river basin, Bulgaria (1989-1998). Open Chemistry, 1(2): 121-136.

Sultana, S., Biswas, P. K., Rahman, A., Sultana, S., and Zaman, M. N. (2016). Risk Factor Assessment of Coal Mine Drainage Water on Surrounding Agricultural Soil: A Case Study at Barapukuria in Bangladesh. Journal of Geoscience and Environment Protection, 4(02): 7.

Tembo, B. D., Sichilongo, K., and Cernak, J. (2006). Distribution of copper, lead, cadmium and zinc concentrations in soils around Kabwe town in Zambia. Chemosphere, 63(3): 497-501.

Tiwary, R., and Dhar, B. (1994). Environmental pollution from coal mining activities in Damodar river basin, India. Mine Water and the Environment, 13(JuneDecember): 1-10.

Tursunov, O., Dobrowolski, J., and Nowak, W. (2015). Catalytic energy production from municipal solid waste biomass: Case study in Perlis, Malaysia. World Journal Environmental Engineering, 3: 7-14.

Zhao, Y., Xia, X., Yang, Z., and Wang, F. (2012). Assessment of water quality in Baiyangdian Lake using multivariate statistical techniques. Procedia Environmental Sciences, 13: 1213-1226. 